\title{
PROPRIEDADES FÍSICAS DO SOLO SOB DIFERENTES SISTEMAS DE MANEJO DA CAPOEIRA NO NORDESTE PARAENSE ${ }^{1}$
}

\author{
Elineuza Faria da Silva Trindade²; Moacir Azevedo Valente ${ }^{3}$; Moisés Mourão Júnior ${ }^{4}$. \\ ${ }^{1}$ Resultados da tese da primeira autora em elaboração junto ao Programa de Doutorado em Ciências Agrárias da \\ Universidade Federal Rural da Amazônia (UFRA)/Embrapa Amazônia Oriental \\ ${ }^{2}$ Engenheira Agrônoma, Doutoranda em Ciências Agrárias pela UFRA/Embrapa Amazônia Oriental, \\ elineuza_trindade@ hotmail.com \\ ${ }^{3}$ Pesquisador aposentado da Embrapa Amazônia Oriental, moavalente@ hotmail.com \\ ${ }^{4}$ Pesquisador da Embrapa Amazônia Oriental, mmourao@cpatu.embrapa.br
}

\begin{abstract}
RESUMO: Um novo modelo de produção baseado em tecnologia de preparo de área sem o uso do fogo está sendo desenvolvido no Nordeste Paraense como alternativa ao preparo tradicional de cortee-queima. Baseado na trituração da capoeira, esse modelo pode contribuir para a melhoria das características produtivas do solo pela manutenção da cobertura do solo. O objetivo deste trabalho foi verificar o efeito de diferentes formas de manejo da capoeira (corte-e-queima e corte-e-trituração) na melhoria das propriedades físicas do solo. A pesquisa foi realizada no Município de Igarapé-Açu, Pará, sob um Neossolo Quartzarênico Órtico típico. Foram avaliadas 3 formas de preparo da terra: 1corte e queima da vegetação em pousio; 2- corte e trituração da vegetação de pousio para cobertura do solo; e, 3- corte, trituração e incorporação da vegetação ao solo, com e sem adubação NPK cada forma, e uma área de capoeira natural como testemunha. O delineamento experimental foi o de blocos ao acaso, com três repetições. As coletas de solo para análise de textura do solo, densidade do solo, porosidade do solo e disponibilidade de água foram realizadas nas profundidades de 0-10, 10-20, 2030 e $30-50 \mathrm{~cm}$, em parcelas de $10,0 \mathrm{~m} \times 12,0 \mathrm{~m}$ em cada tratamento, e analisadas segundo a metodologia da Embrapa (1997). As médias dos resultados analíticos foram comparadas pelo teste de Tukey a 5\%. Os resultados indicaram que o sistema baseado na trituração da capoeira aliado a complementação através da adubação mineral apresenta maior potencial para a manutenção da qualidade física do solo em relação ao sistema com queima da vegetação secundária ao longo do tempo e que a disponibilidade de água às plantas no solo sob trituração da capoeira é maior que no solo sob queima da capoeira nas camadas mais próximas à superfície.
\end{abstract}

PALAVRAS-CHAVE: agricultura familiar, manejo do solo, sistema de corte e trituração da capoeira.

\section{PHYSICAL PROPERTIES OF A SOIL UNDER DIFFERENT MANAGEMENT SYSTEMS OF THE BUSH IN THE NORTHEAST OF THE STATE OF PARÁ, BRAZIL}

\begin{abstract}
A new model of production technology - based staging area without the use of fire is being developed in the Northeast of the State of Pará, Brazil, as alternative to the traditional preparation of slash and burn. Based in the trituration of the bush, this model could contribute to the improved of productive characteristics in the soil by maintance the cover in the soil. The objective of this study was to verify the effect of differents forms of management of the bush (slash and burn e slash and trituration) in improvement of physical properties of a soil passage of time. A pesquisa foi realizada no Municipality of Igarapé-Açu, Pará, under a Entisol Typic. Three forms of land preparation was evaluated: 1- slash and burn of vegetation in fallow; 2- slush and trituration of vegetation in fallow to be used as vegetative cover of the soil; and, 3- slash, trituration and incorporation of vegetation to the soil, with and without NPK, and a natural bushy area as the control plot. The experimental design was random blocks, with three repetitions. The collections of soil for analysis of soil texture, soil bulk density, soil porosity and water availability was made in the upper $0-10,10-20,20-30$ and $30-50 \mathrm{~cm}$ of the soil, in plots of $10.0 \mathrm{~m} \mathrm{x} 12.0 \mathrm{~m}$ in each treatment, and was analyzed according to Embrapa's methodology (1997). The analytical result averages were compared to Tukey test at $5 \%$. The results indicate that the system based on slash
\end{abstract}

Agroecossistemas, v. 4, n. 1, p. 50-67, 2012 
and trituration of the bush and the use of mineral fertilization presents greater potential for maintenance of the physical quality of the soil in relation to burning the secondary vegetation over time, and that the water availability to plants in the soil under trituration of the bush is greater than in the soil under slash and burn the secondary vegetation in the layers closer to the soil surface.

Keywords: family agriculture, soil management, trituration of the bush.

\section{INTRODUÇÃO}

As capoeiras podem ser definidas como áreas de crescimento espontâneo de vegetação secundária proveniente do processo sucessional dos ecossistemas florestais naturais, e surgem a partir do abandono da área utilizada após o desenvolvimento de atividades como a agricultura e pecuária, assumindo um papel central no agroecossistema da agricultura itinerante.

No nordeste do Pará, região dominada por este tipo de vegetação (OLIVEIRA; FERREIRA; SABOGAL, 2001), e com fundamental importância para a manutenção da atividade agrícola e geração de renda, torna-se necessário mais conhecimento sobre formas de uso eficientes e sustentáveis desta vegetação (SCHWARTZ, 2007), uma vez que em meio ao mosaico que elas formam, encontra-se muitas áreas degradadas, com solos pobres em nutrientes e com problemas estruturais.

Por constituir-se em uma das áreas de colonização agrícola mais antiga na Amazônia brasileira e que sofreu intenso processo de desmatamentos e queimadas, essa região experimenta um novo modelo de produção baseado em tecnologia de preparo de área sem o uso do fogo, através da trituração da vegetação secundária, nova modalidade de plantio direto desenvolvida pela Embrapa Amazônia Oriental, através do Projeto Tipitamba, em parceria com o Governo Alemão (BERVALD, 2005).

Essa tecnologia consiste do corte e trituração da vegetação, em uma única operação, deixando o material sobre o solo na forma de cobertura morta. Os plantios dos cultivos são feitos diretamente, em sistema de plantio direto, cuja palhada (cobertura morta) é produzida pela capoeira (BERVALD, 2005).

Entre as vantagens desta tecnologia estão, a melhoria das características produtivas do solo e a flexibilização do calendário agrícola com minimização dos impactos ambientais provocados pela agricultura itinerante. .

O sistema baseado na trituração da capoeira promove a proteção do solo contra os impactos das gotas de chuva, diminuindo os processos erosivos e o escorrimento superficial. Segundo Mafra (2010), a eliminação da capa superficial do solo tem reflexos não apenas na degradação física (aumento da compactação; menor percolação de água; aeração deficiente; dificuldade para o crescimento de raízes), mas também na perda 
de fertilidade do solo, uma vez que os nutrientes presentes nas camadas superiores (mais férteis) são incorporados ao solo erodido.

Por esta razão, torna-se relevante uma maior atenção nos estudos em relação à qualidade física do solo, pois uma vez desgastado ele tem a sua fertilidade diminuída, o que influencia marcantemente na exploração agrícola, diminuindo consideravelmente as condições para as plantas produzirem economicamente.

No âmbito do projeto, estudos realizados por Costa (2008), Gama (2002) e Marcolan, Locatelli e Fernandes (2009) indicam melhorias principalmente em relação à fertilidade do solo, enquanto que Locatelli et al. (2011) e Trindade et al. (2009) indicam melhoria na qualidade física dos solos que trabalharam, porém, resultados relacionados à física do solo ainda são incipientes quanto ao impacto advindo do corte e trituração da capoeira.
O objetivo deste trabalho foi verificar o efeito de diferentes formas de manejo da capoeira (corte-e-queima e corte-e-trituração) na melhoria das propriedades físicas do solo.

\section{MATERIAL E MÉTODOS}

A pesquisa foi realizada na comunidade Cumaru, em área experimental da Embrapa Amazônia Oriental, no Município de IgarapéAçu, Nordeste do Estado do Pará, entre as coordenadas geográficas de $1^{\circ} 11^{\prime} \mathrm{S}$ e $47^{\circ} 34^{\prime}$ W, sob um Neossolo Quartzarênico Órtico típico (EMBRAPA, 2006), cujos dados granulométricos estão expressos na Tabela 1. O clima da região é intermediado entre Aw/Am, pela classificação de Köppen, chuvoso, apresentando estação seca de cinco meses, de agosto a dezembro, com temperatura anual variando entre 21 e $32{ }^{\circ} \mathrm{C}$, precipitação de aproximadamente $2.500 \mathrm{~mm}$, umidade relativa do ar de aproximadamente $84 \%$ e brilho solar de 192,8 h/mês (BASTOS; PACHECO, 1999).

Tabela 1. Resultado da análise granulométrica representativa da área de estudo.

\begin{tabular}{|c|c|c|c|c|c|c|}
\hline \multirow{3}{*}{$\begin{array}{l}\text { Prof. } \\
\text { cm }\end{array}$} & \multicolumn{3}{|c|}{ Areia } & \multirow[t]{2}{*}{ Silte } & \multirow{2}{*}{$\begin{array}{c}\text { Argila } \\
\text { Total } \\
\end{array}$} & \multirow{2}{*}{$\begin{array}{r}\text { Classe } \\
\text { textural }\end{array}$} \\
\hline & Grossa & Fina & Total & & & \\
\hline & \multicolumn{5}{|c|}{$\mathrm{g} \mathrm{kg}^{-1}$ de solo } & \\
\hline $0-10$ & 520 & 387 & 907 & 40 & 53 & Areia \\
\hline $10-20$ & 532 & 370 & 902 & 38 & 60 & Areia \\
\hline $20-30$ & 446 & 450 & 896 & 24 & 80 & Areia franca \\
\hline $30-50$ & 482 & 343 & 825 & 75 & 100 & Areia franca \\
\hline
\end{tabular}

Fonte: Dados da pesquisa. 
Os estudos foram conduzidos em áreas de pousio da vegetação secundária com idade de quatro anos, onde as parcelas experimentais constaram de $120 \mathrm{~m}^{2}(10,0 \mathrm{x}$ $12,0 \mathrm{~m})$ e área total de $5.000 \mathrm{~m}^{2}(50,0 \times 100,0$ $\mathrm{m})$. O delineamento experimental utilizado foi o de blocos ao acaso, em esquema fatorial (7x4x2), com três repetições.

As parcelas constituíram-se pelas formas de preparo da terra: Queima da vegetação + adubação química $(\mathrm{Q}+)$; Queima da vegetação sem adubação química (Q-); Cobertura com vegetação triturada + adubação química (C+); Cobertura com vegetação triturada sem adubação química (C); Trituração e incorporação da vegetação + adubação química (I+); Trituração e incorporação da vegetação sem adubação química (I-) e Capoeira natural (CAP). As amostras de solo foram coletadas em duas épocas: 1995 (solo sob capoeira - antes da instalação do experimento) e em 2010 (15 anos após a implantação do experimento), em quatro profundidades $(0-10,10-20,20-30$ e $30-50 \mathrm{~cm})$.

No processo de preparo de área, a cobertura do solo com biomassa vegetal triturada foi realizada por meio do equipamento Tritucap (triturador de capoeira motomecanizado) acoplado a um trator de rodas. Nas parcelas com incorporação do material, o processo foi feito manualmente, com a ajuda de enxada, até uma profundidade de aproximadamente $15 \mathrm{~cm}$.
As parcelas foram cultivadas em regime de sequeiro com o arroz (Oryza sativa cv. Xingu) em rotação com o feijão-caupi (Vigna unguiculata cv. BR3-Tracuateua) e a mandioca (Manihot esculenta cv. Pretinha) de acordo com o calendário agrícola da região.

Nas parcelas com fertilizantes foram utilizados como fonte de NPK a uréia, o superfosfato triplo e o cloreto de potássio, respectivamente, nas doses 50,25 e $25 \mathrm{~kg} \mathrm{ha}^{-1}$ para o arroz e $10,22,42 \mathrm{~kg} \mathrm{ha}^{-1}$ para o feijãocaupi. Para a mandioca não houve adubação específica, sendo considerado o efeito residual do fertilizante aplicado nas culturas do arroz e do feijão-caupi.

A densidade, porosidade e água do solo foram determinadas segundo a metodologia da Embrapa (1997), sendo que para o cálculo de água disponível foram considerados, respectivamente, como capacidade de campo (CC) e ponto de murcha permanente (PMP) os potenciais mátricos de -10 e $-1500 \mathrm{kPa}$.

Para efeito de análise estatística foi empregado o modelo de análise de variância (ANOVA) com medidas repetidas (LITTELL et al., 2006). Tais análises foram conduzidas com auxílio da planilha Excel, do SAS System e do pacote STATISTICA 5.5. Dada a significância dos efeitos, a ordenação univariada dos valores médios, com representação do respectivo desvio padrão, foi obtida por meio do teste de Tukey a $5 \%$ de probabilidade. 


\section{RESULTADOS E DISCUSSÃO}

\section{DENSIDADE DO SOLO}

Os resultados médios para as variáveis, densidade do solo, porosidade total, macroporosidade e microporosidade estão apresentados na Tabela 2.

Observa-se que no geral, os valores de densidade do solo determinados nos diferentes sistemas de manejo estão dentro da faixa encontrada em solos minerais $(1,10$ a 1,60 $\mathrm{kg} \mathrm{dm}^{-3}$ ) considerados ideais para um bom desenvolvimento do sistema radicular das plantas (KEIHL, 1979), no entanto, é comum verificar-se tendência de aumento da densidade do solo quando os mesmos são submetidos a diferentes sistemas de manejo em relação ao seu estado natural, principalmente nas duas primeiras camadas (0-10 e 10-20 $\mathrm{cm}$ de profundidade).

Verifica-se que apesar da semelhança estatística, todos os tratamentos apresentaram tendência de aumento da densidade do solo em relação à testemunha (CAP), sendo os menores valores observados nos tratamentos baseados no sistema alternativo de corte e trituração da capoeira, independente de adubação (C e I), sendo mais baixos naqueles que foram adubados.

Tabela 2. Valores médios de densidade do solo $\left(\mathrm{kg} \mathrm{dm}^{-3}\right)$, porosidade total, macroporosidade e microporosidade $\left(\mathrm{m}^{3} \mathrm{~m}^{-3}\right)$, nos diferentes tratamentos e profundidades.

\begin{tabular}{|c|c|c|c|c|c|c|c|c|c|c|c|c|c|c|c|}
\hline VARIÁVEL & $\begin{array}{c}\text { PROF } \\
(\mathbf{c m})\end{array}$ & CAP & & $\mathbf{Q}(-)$ & & $\mathbf{C}(-)$ & & $\mathbf{I}(-)$ & & $\mathbf{Q}(+)$ & & $\mathrm{C}(+)$ & & $\mathbf{I}(+)$ & \\
\hline \multirow{4}{*}{ Densidade do Solo } & $0-10$ & 1,27 & A & 1,41 & A & 1,34 & A & 1,34 & A & 1,38 & A & 1,32 & A & 1,30 & A \\
\hline & $10-20$ & 1,40 & $\mathrm{AB}$ & 1,44 & $\mathrm{AB}$ & 1,46 & $\mathrm{AB}$ & 1,46 & $\mathrm{AB}$ & 1,55 & $\mathrm{AB}$ & 1,46 & $\mathrm{AB}$ & 1,36 & B \\
\hline & $20-30$ & 1,47 & A & 1,45 & A & 1,54 & A & 1,50 & A & 1,56 & A & 1,47 & A & 1,47 & A \\
\hline & $30-50$ & 1,48 & A & 1,45 & A & 1,55 & $\mathrm{~A}$ & 1,50 & A & 1,58 & $\mathrm{~A}$ & 1,47 & A & 1,47 & $\mathrm{~A}$ \\
\hline \multirow{4}{*}{ Porosidade total } & $0-10$ & 0,52 & $\mathrm{~A}$ & 0,44 & B & 0,46 & $\mathrm{AB}$ & 0,44 & $\mathrm{~B}$ & 0,45 & $\mathrm{AB}$ & 0,47 & $\mathrm{AB}$ & 0,48 & $\mathrm{AB}$ \\
\hline & $10-20$ & 0,45 & A & 0,42 & $\mathrm{AB}$ & 0,41 & $\mathrm{AB}$ & 0,40 & $\mathrm{AB}$ & 0,37 & B & 0,42 & $\mathrm{AB}$ & 0,44 & $\mathrm{AB}$ \\
\hline & $20-30$ & 0,45 & A & 0,42 & $\mathrm{AB}$ & 0,38 & $\mathrm{AB}$ & 0,39 & $\mathrm{AB}$ & 0,36 & $\mathrm{AB}$ & 0,40 & $\mathrm{AB}$ & 0,39 & $\mathrm{AB}$ \\
\hline & $30-50$ & 0,45 & $\mathrm{~A}$ & 0,42 & $\mathrm{AB}$ & 0,38 & $\mathrm{AB}$ & 0,39 & $\mathrm{AB}$ & 0,36 & $\mathrm{AB}$ & 0,40 & $\mathrm{AB}$ & 0,39 & $\mathrm{AB}$ \\
\hline \multirow{4}{*}{ Macroporosidade } & $0-10$ & 0,39 & A & 0,37 & $\mathrm{AB}$ & 0,35 & $\mathrm{AB}$ & 0,33 & $\mathrm{AB}$ & 0,30 & $\mathrm{AB}$ & 0,36 & $\mathrm{AB}$ & 0,38 & A \\
\hline & $10-20$ & 0,33 & A & 0,31 & A & 0,31 & A & 0,23 & B & 0,22 & B & 0,29 & $\mathrm{AB}$ & 0,32 & A \\
\hline & $20-30$ & 0,29 & A & 0,27 & A & 0,27 & A & 0,22 & $\mathrm{AB}$ & 0,16 & B & 0,26 & A & 0,28 & A \\
\hline & $30-50$ & 0,29 & $\mathrm{~A}$ & 0,26 & $\mathrm{~A}$ & 0,26 & $\mathrm{~A}$ & 0,22 & $\mathrm{~A}$ & 0,16 & $\mathrm{~B}$ & 0,26 & A & 0,24 & A \\
\hline \multirow{4}{*}{ Microporosidade } & $0-10$ & 0,13 & A & 0,12 & A & 0,11 & A & 0,11 & A & 0,15 & A & 0,11 & A & 0,10 & A \\
\hline & $10-20$ & 0,15 & $\mathrm{~A}$ & 0,13 & $\mathrm{~A}$ & 0,11 & A & 0,17 & $\mathrm{~A}$ & 0,15 & A & 0,13 & A & 0,12 & A \\
\hline & $20-30$ & 0,16 & A & 0,13 & A & 0,11 & A & 0,18 & A & 0,20 & A & 0,15 & A & 0,12 & A \\
\hline & $30-50$ & 0,16 & A & 0,15 & $\mathrm{~A}$ & 0,11 & $\mathrm{~A}$ & 0,18 & A & 0,20 & A & 0,15 & A & 0,15 & $\mathrm{~A}$ \\
\hline
\end{tabular}

Fonte: Dados da pesquisa.

Com base na Figura 1, pode-se observar claramente o efeito do adubo na diminuição da densidade do solo principalmente nos tratamentos com trituração da capoeira que 
foram adubados. Nota-se, independente da profundidade analisada, que o tratamento $\mathrm{I}(+)$ apresentou tendência de melhores resultados, ou seja, menor densidade, principalmente na segunda camada $(10-20 \mathrm{~cm})$, em que foi estatisticamente superior aos demais $(1,36 \mathrm{~kg}$ $\mathrm{dm}^{-3}$ de solo, contra $1,46 \mathrm{~kg} \mathrm{dm}^{-3}$ e $1,55 \mathrm{~kg}$ $\mathrm{dm}^{-3}$ de solo, respectivamente para $\mathrm{C}(+)$ e $\mathrm{Q}(+))$. sem adubo

com adubo

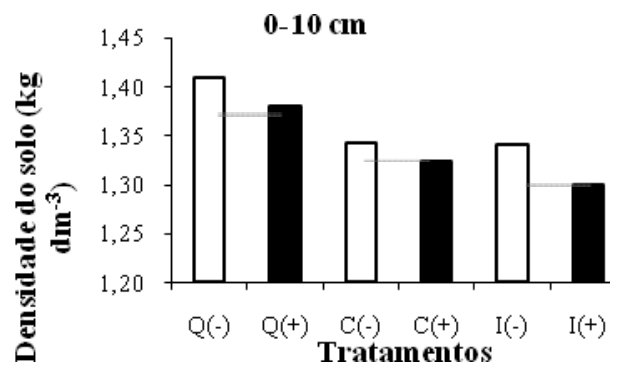

20-30 cm

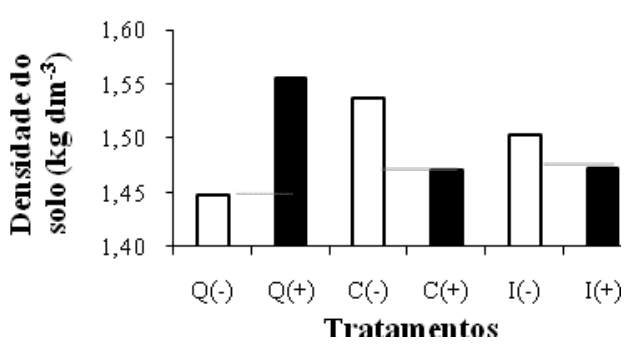

$10-20 \mathrm{~cm}$

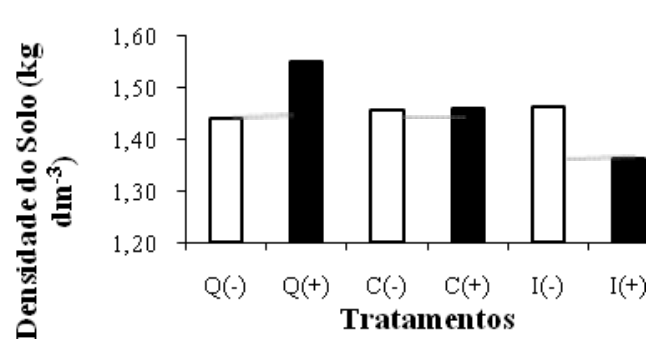

$30-50 \mathrm{~cm}$

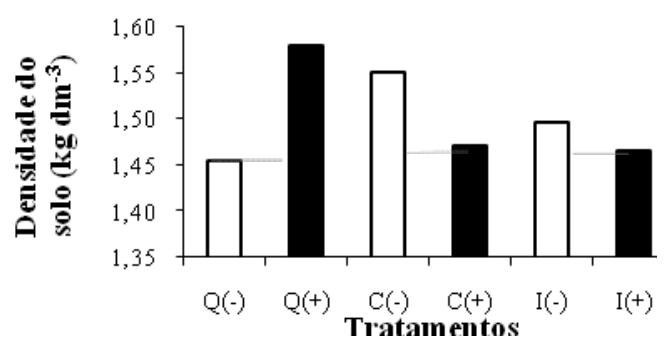

Figura 1. Representação gráfica para a variável densidade do solo, considerando o fator adubação, nos diferentes sistemas de manejo e profundidades do solo.

Fonte: Dados da pesquisa.

A fertilização certamente promoveu um efeito indireto na densidade do solo devido sua influência no aumento considerável do sistema radicular das plantas, que por sua vez causa a descompactação das partículas do solo com consequente diminuição da densidade do solo, como citado por Oliveira et al. (2005).
Santos et al. (2005) avaliando o efeito da compactação e adubação no crescimento de plantas de milho em solo semelhante ao deste estudo, observou que a aplicação de doses crescentes de fósforo $(\mathrm{P})$, associada a calagem e fertilização básica com macro e micronutrientes, funcionou como um fator de aliviamento da compactação do solo, 
resultando em uma maior produção para um mesmo grau de compactação.

Outro fator importante para a diminuição da densidade do solo é a incorporação da biomassa triturada até a profundidade de $15 \mathrm{~cm}$, uma vez que esta prática de manejo com o passar dos anos causa efeito positivo nas propriedades físicas do solo, sobretudo na melhoria da estruturação, deixando o solo mais resistente às ações do intemperismo físico e conduzindo a formação de grânulos que o deixarão mais poroso e permeável (SOUZA,1989).

As parcelas com queima da vegetação, independente de fertilização, foram as que apresentaram tendência de maiores valores de densidade do solo. Embora estatisticamente semelhantes aos outros tratamentos, à falta de cobertura do solo associada ao entupimento dos poros pelas cinzas pode ter provocado uma sensível compactação deste solo em relação à testemunha (CAP) ao longo dos 15 anos de alternância de períodos de preparo de solo-cultivo-pousio.

A prática da queima como preparo de área também causa prejuízos praticamente irreparáveis, uma vez que destrói os resíduos orgânicos da camada superficial que são importantíssimos para a manutenção da estrutura do solo. Alia-se a isso a destruição dos macro e microorganismos do solo que igualmente facilitam a desagregação das partículas do solo e consequentemente melhoram suas propriedades físicas. É sabido que esta técnica de preparo do solo ocasiona danos consideráveis ao ecossistema como um todo, especialmente na região nordeste do Estado do Pará, área de colonização antiga com utilização desta prática. Gama (2002) e Bervald (2005) enfatizam que a insustentabilidade dessa prática está fortemente relacionada à crescente densidade populacional na região, com consequente diminuição na disponibilidade de terras, o que o aumenta a pressão sobre a floresta e a degradação dos solos, pois o pousio da vegetação torna-se cada vez mais curto e insuficiente para a acumulação de nutrientes durante a regeneração da capoeira.

Nas duas últimas camadas (20-30 e 30$50 \mathrm{~cm}$ de profundidade), independente do sistema de uso, praticamente não houve efeito dos tratamentos influenciando nesta característica, havendo apenas uma tendência natural de aumento dos valores de densidade do solo devido ao adensamento natural provocado pelo peso das camadas superiores sobre as subjacentes e pela diminuição de matéria orgânica ao longo do perfil do solo.

Destaca-se, de modo geral, que o sistema alternativo de corte e trituração da capoeira não provocou alterações significativas na densidade solo ao longo de quinze anos de manejo do solo neste sistema. $\mathrm{O}$ peso do conjunto trator-triturador por um longo período também não contribuiu para elevar a densidade do solo a valores maiores que o das áreas com queima, sugerindo que a cobertura proporcionada ao solo pelo material 
triturado amortece a pressão da máquina sobre o solo.

Comparando a influência do sistema de plantio direto com uma área de mata nativa na variação da densidade do solo em um Nitossolo Vermelho distroférrico, Assis e Lanças (2005) identificaram que somente a partir do décimo segundo ano de instalação é que o sistema de plantio direto conseguiu se igualar aos valores de densidade do solo encontrado na mata nativa, para a camada de 0-5 cm, evidenciando o efeito da necessidade de um longo tempo neste sistema de manejo para a recuperação estrutural do solo, a semelhança do que pode está ocorrendo na área desta pesquisa.

A hipótese da baixa compressão do solo pela tritucap em razão da camada de cobertura morta está de acordo com os estudos de Bervald (2005) e Cardoso Júnior et al. (2007). Até $20 \mathrm{~cm}$ de profundidade os autores não observaram diferenças significativas para a densidade do solo entre tratamentos com corte e queima e com corte e trituração da capoeira, no entanto encontraram um sensível aumento numérico nas áreas com o sistema alternativo, afirmando que esses valores mais elevados, apesar do uso da tritucap, não chegam a ser prejudiciais às plantas visto que o nível de compactação considerado prejudicial está por volta de um acréscimo entre $15 \%$ e $20 \%$ no valor médio inicial da densidade do solo.

Estes dados corroboram com os de Marcolan, Locatelli e Fernandes (2009) em Rondônia, onde concluíram que o sistema de manejo com corte e trituração da capoeira, embora sem significância estatística, propiciou tendência de menor densidade do solo e menor resistência à penetração em relação ao manejo com derruba e queima da capoeira, o que também foi verificado por Mulumba e Lal (2008) em estudo de longa duração sobre os efeitos da cobertura morta nas propriedades físicas do solo.

Silva (2009) verificou valores de densidade do solo muito próximos dentro dos tratamentos com queima e com trituração da capoeira no Estado do Amapá. Para o autor, embora no sistema de plantio direto haja ausência de movimentação do solo e manutenção de resíduos orgânicos na superfície do solo podendo melhorar processos intrínsecos do solo, como a estrutura e a dinâmica físico-hídrica, as alterações das propriedades físicas dependem de processos lentos. Desta forma, também na área desta pesquisa os tratamentos sem queima, apesar do longo tempo de implantação, ainda não foram capazes de alterar (diminuir) significativamente a densidade do solo.

\section{POROSIDADE DO SOLO}

Os resultados das análises de porosidade do solo (total, macroporosidade e microporosidade), apresentados na Tabela 2, indicam haver diferença estatística significativa entre tratamentos apenas para porosidade total e macroporosidade nas duas 
primeiras camadas analisadas (0-10 e 10-20 $\mathrm{cm})$.

Considerando a porosidade total, de modo geral todos os valores médios absolutos encontrados nos diferentes tratamentos são inferiores aos da testemunha (CAP), concordando com as afirmações de Araújo, Tormena e Silva (2004) quando avaliaram algumas propriedades indicadoras da qualidade física de um Latossolo Vermelho distrófico da região Noroeste do Paraná, cultivado e sob mata nativa. Segundo estes autores, a porosidade do solo pós-cultivado é significativamente reduzida em virtude do aumento da compactação, que é evidenciada pelo aumento da densidade do solo. Os resultados mais evidentes referem-se aos valores observados na macroporosidade do solo, pois os fatores por eles mencionados causam uma diminuição no tamanho dos agregados maiores reduzindo, em consequência, o tamanho dos poros.

Dias júnior (2000) salientam que o processo de compactação refere-se à compressão do solo não saturado promovendo o aumento da sua densidade e redução do seu volume, resultante da expulsão do ar dos poros do solo, diminuindo a porosidade total, principalmente a macroporosidade. Neste caso, pode haver um impedimento ao desenvolvimento radicular e ao movimento de água no perfil. Da mesma forma, Dalal e Chan (2000) afirmam que a redução da quantidade de matéria orgânica em solos sob cultivo tende a aumentar os valores de densidade do solo, refletido por menores valores de macroporosidade do solo em comparação a solos sob floresta natural.

Ao longo de quinze anos de alternância de períodos de corte-e-queima, cultivo e pousio, observa-se que houve diferença estatística significativa para porosidade total entre tratamentos não adubados e adubados apenas na camada superficial $(0-10 \mathrm{~cm}$ de profundidade), sendo que os que receberam adubação mineral apresentaram os melhores resultados. Certamente a fertilização do solo causa um aumento considerável do sistema radicular das plantas cultivadas que ao se desenvolverem lateralmente promovem a descompactação do solo levando a um aumento da quantidade de poros, principalmente macroporos.

Nota-se que para as três variáveis analisadas (porosidade total, macroporosidade e microporosidade) o sistema de manejo com trituração da capoeira apresenta tendência a ser superior ao sistema com queima da capoeira. A presença da cobertura do solo nos tratamentos sem queima contribuiu para a manutenção da matéria orgânica do solo e sensível diminuição dos efeitos que influenciam no aumento da densidade e consequente diminuição da porosidade do solo. Resultados semelhantes foram verificados por Marcolan, Locatelli e Fernandes (2009), os quais atribuíram a tendência de menor densidade do solo e menor resistência à penetração do solo sob capoeira triturada, em relação à queimada, ao 
aporte de material vegetal protegendo a superfície do solo contra eventos tais como o impacto das gotas de chuva, que causam a diminuição da qualidade estrutural do solo.

Como esperado, os valores médios encontrados na Tabela 1 refletem claramente a diminuição da macroporosidade e aumento da microporosidade a medida que se aprofunda no perfil do solo. Isto pode ser explicado pela textura (Tabela 1), cuja fração grosseira (areia) diminui com a profundidade do solo, havendo aumento da fração mais fina (argila), bem como pela também natural diminuição da matéria orgânica do solo nas camadas mais inferiores do solo.

Nas duas primeiras camadas (0-10 e 10$20 \mathrm{~cm}$ de profundidade), considerando-se os fatores adubação e cobertura do solo, ambos os tratamentos baseados na trituração da capoeira $(\mathrm{C}+\mathrm{e} \mathrm{I}+)$ apresentaram-se superiores ao da parcela com queima, sendo estatisticamente melhores que o tratamento (Q+) na segunda camada, possivelmente devido ao efeito da cobertura contribuindo com a minimização dos impactos das gotas de chuva sobre o solo.

A Figura 2 representa graficamente a variação da porosidade do solo, considerando apenas o fator presença de adubo, nos diferentes tratamentos e profundidades do solo. A ilustração é clara ao apresentar, estatisticamente, a inferioridade do sistema com queima na melhoria da qualidade física do solo. É possível observar com maior evidência a baixa quantidade de macroporos e a consequente maior quantidade de microporos no tratamento $\mathrm{Q}(+)$ em relação aos demais, aumentando o processo que leva à compactação gradual do solo, como constatado na variável densidade do solo.

Para os tratamentos $\mathrm{C}(+)$ e $\mathrm{I}(+)$, verifica-se o contrário. Neles há um favorecimento à melhoria da qualidade física a partir dos resultados de porosidade do solo, cujos valores de porosidade total $(0,39$ a 0,48 $\mathrm{m}^{3} \mathrm{~m}^{-3}$ ) encontram-se dentro da faixa proposta por Hillel (1970), com todos os valores de macroporosidade $\left(0,24\right.$ a $\left.0,38 \mathrm{~m}^{3} \mathrm{~m}^{-3}\right)$ acima do limite crítico para o desenvolvimento radicular das plantas cultivadas, corroborando com os resultados encontrados por Trindade et al. (2009) em solo sob diferentes sistemas de uso e manejo. O tratamento $\mathrm{Q}(+)$, após 15 anos de cultivo, apresentou, de modo geral, valores de porosidade total e de macroporosidade no limite crítico, ou abaixo deste, para o desenvolvimento das raízes.

Segundo Wolters (2000), o fogo destrói, além dos resíduos orgânicos vegetais, grande quantidade de organismos da fauna edáfica, principalmente no horizonte orgânico. Dentre esses organismos, os macro-invertebrados (formigas, minhocas, cupins, entre outros) têm grande importância para a Física do Solo pela capacidade de cavar eficientemente o solo e produzir uma grande variedade de poros. Esse fator pode ser considerado de grande importância quando do uso da trituração da capoeira, uma vez que não há necessidade de queimar a biomassa para 
preparar o solo para cultivo, logo, mantendo uma quantidade significativa da fauna natural do solo auxiliando na melhoria da porosidade do solo.
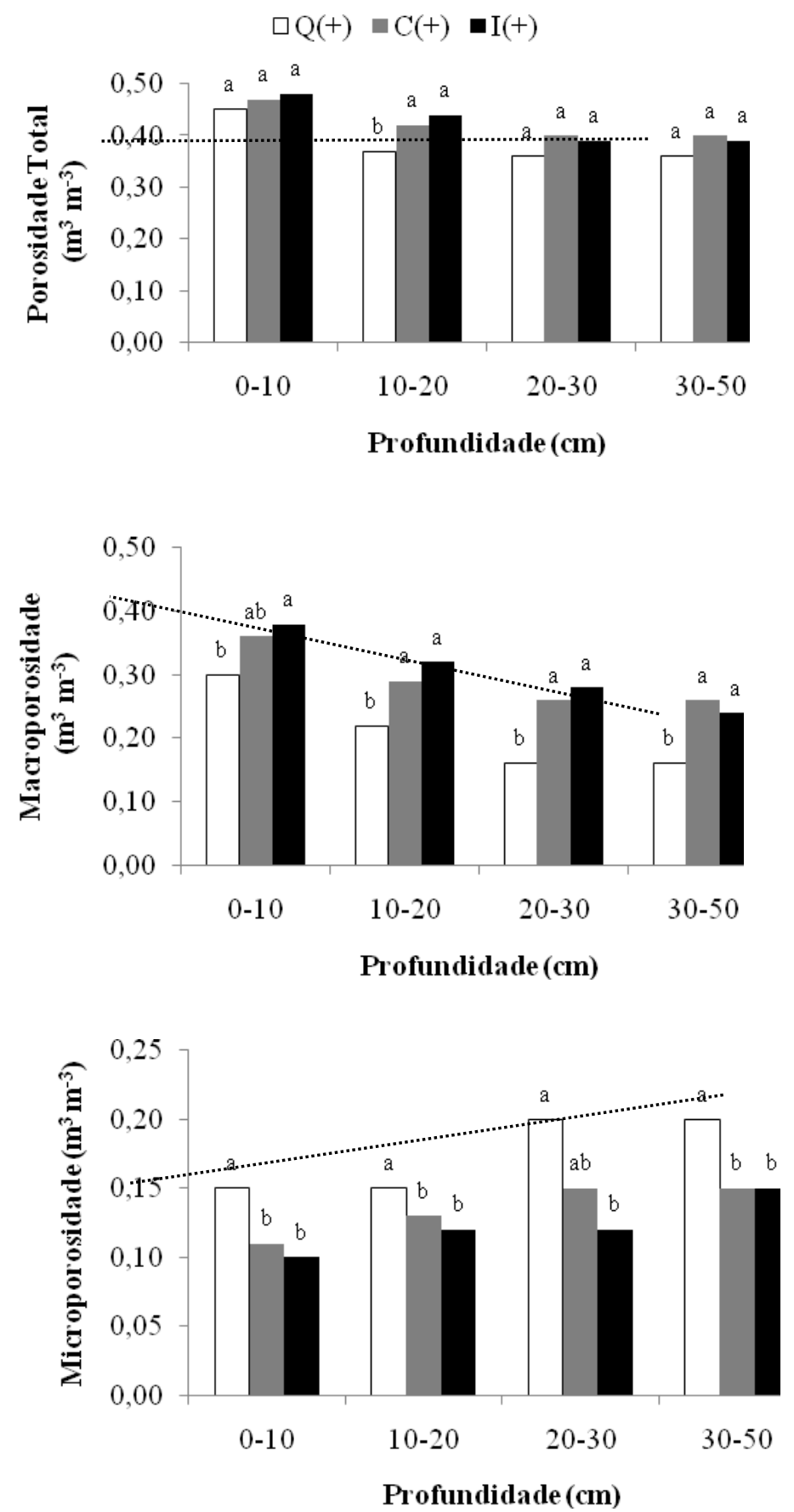

Figura 2. Porosidade do solo (total, macroporosidade e microporosidade) nos tratamentos que sofreram adubação. Letras iguais dentro de cada profundidade não diferem estatisticamente entre si pelo teste de Tukey a 5\%. Fonte: Dados da pesquisa.

Lins-Teixeira et al. (2007) avaliando a comunidade de macro-invertebrados do solo sob capoeiras trituradas no Estado do Amazonas, encontraram uma densidade de 
172 indivíduos por $\mathrm{m}^{2}$ nas áreas em repouso há 5 anos. Em Marabá, Estado do Pará, pesquisas revelaram que a densidade total de macro-invertebrados em áreas de pastagem é de, pelo menos, a metade daquela encontrada em áreas de florestas (DESJARDINS et al., 2004). Estes resultados podem vir a somar na indicação da tecnologia de trituração da capoeira como alternativa ao uso do fogo na melhoria da qualidade física do solo.

Nas camadas de 20-30 e 30-50 cm de profundidade, independente do tratamento (adubados ou não), os valores encontrados são, em geral, absolutamente idênticos, indicando que nestas profundidades não há interferência dos sistemas de manejo na porosidade do solo, o que pode ser visualizado pelas linhas de tendência a partir da Figura 2.

No caso da porosidade total observa-se uma linha horizontal demonstrando que nenhum tratamento interfere no total de poros principalmente nas duas últimas camadas. Nos casos da macro e microporosidade observa-se nitidamente as linhas de tendência decrescente e crescente, respectivamente. Destaca-se aí o tratamento com queima da biomassa vegetal evidenciando o efeito danoso desta prática no preparo de área para cultivo, ao contrário dos tratamentos com trituração da capoeira, com significativa melhoria nos valores dessas variáveis em relação aos resultados referentes à queima considerando-se a importância da adubação nesse processo, à semelhança dos resultados de densidade do solo.

Resultados indicativos de melhoria da porosidade do solo no sistema de plantio direto na capoeira foram encontrados por Locatelli et al. (2012), em Rondônia, e por Trindade et al. (2009) e Bervald (2005), no Nordeste do Pará, cujos valores dessa variável em experimento de curta duração não diferiram estatisticamente da testemunha, conservando-se dentro dos limites críticos para o crescimento radicular das culturas.

Comparando os dois sistemas de manejo aqui estudados, o resultado apresentado pode ser considerado como um indicador para a substituição da queima pelo sistema de trituração da capoeira em relação à porosidade do solo no longo prazo.

\section{ÁGUA DO SOLO}

$\mathrm{Na}$ Tabela 3 estão apresentados os valores médios obtidos para capacidade de campo (CC), ponto de murcha permanente (PMP) e água disponível (AD) para os diferentes tratamentos e profundidades do solo.

Observa-se que para os parâmetros capacidade de campo e água disponível os valores são relativamente baixos, estando estes relacionados diretamente com a textura e estrutura do solo estudado.

Campbell (2006) explica que a classe textural das areias, como no caso deste estudo, apresenta uma textura mais grossa, tendendo a uma maior drenagem, resultando 
em percentagens menores de umidade do solo, ficando os valores de capacidade de campo na faixa de 0,03 a $0,17 \mathrm{~m}^{3} \mathrm{~m}^{-3}$, enquanto que em solos de textura mais fina esses teores são elevados, atingindo $0,42 \mathrm{~m}^{3}$ $\mathrm{m}^{-3}$ de umidade volumétrica, podendo variar de acordo com a densidade do solo. A quantidade de água na capacidade de campo nas camadas mais superficiais do solo também pode ser influenciada pela alta evaporação em virtude das condições climáticas da região, podendo a água do perfil passar diretamente para a atmosfera, como comentado por Torres (2012).

Tabela 3. Valores médios de capacidade de campo (CC), água disponível (AD) e ponto de murcha permanente (PMP), em $\mathrm{m}^{3} \mathrm{~m}^{-3}$, para os diferentes tratamentos nas diferentes profundidades.

\begin{tabular}{|c|c|c|c|c|}
\hline \multirow[t]{2}{*}{ TRAT. } & \multirow{2}{*}{$\begin{array}{c}\text { PROF. } \\
(\mathrm{cm})\end{array}$} & $\mathrm{CC}$ & AD & PMP \\
\hline & & \multicolumn{3}{|c|}{$\mathbf{m}^{3} \mathbf{m}^{-3}$} \\
\hline \multirow[t]{4}{*}{ CAP } & $0-10$ & 0,10 & 0,08 & 0,02 \\
\hline & $10-20$ & 0,12 & 0,10 & 0,02 \\
\hline & $20-30$ & 0,13 & 0,11 & 0,02 \\
\hline & $30-50$ & 0,15 & 0,13 & 0,02 \\
\hline \multirow[t]{4}{*}{ Q- } & $0-10$ & 0,10 & 0,06 & 0,04 \\
\hline & $10-20$ & 0,10 & 0,05 & 0,05 \\
\hline & $20-30$ & 0,10 & 0,07 & 0,03 \\
\hline & $30-50$ & 0,14 & 0,10 & 0,04 \\
\hline \multirow[t]{4}{*}{ C- } & $0-10$ & 0,08 & 0,06 & 0,02 \\
\hline & $10-20$ & 0,09 & 0,05 & 0,05 \\
\hline & $20-30$ & 0,09 & 0,05 & 0,04 \\
\hline & $30-50$ & 0,10 & 0,08 & 0,02 \\
\hline \multirow[t]{4}{*}{ I- } & $0-10$ & 0,26 & 0,22 & 0,04 \\
\hline & $10-20$ & 0,17 & 0,13 & 0,04 \\
\hline & $20-30$ & 0,10 & 0,07 & 0,04 \\
\hline & $30-50$ & 0,14 & 0,12 & 0,02 \\
\hline \multirow[t]{4}{*}{ Q+ } & $0-10$ & 0,06 & 0,02 & 0,04 \\
\hline & $10-20$ & 0,06 & 0,03 & 0,03 \\
\hline & $20-30$ & 0,09 & 0,05 & 0,04 \\
\hline & $30-50$ & 0,11 & 0,10 & 0,01 \\
\hline \multirow[t]{4}{*}{$\mathrm{C}+$} & $0-10$ & 0,10 & 0,08 & 0,02 \\
\hline & $10-20$ & 0,12 & 0,11 & 0,01 \\
\hline & $20-30$ & 0,12 & 0,08 & 0,04 \\
\hline & $30-50$ & 0,12 & 0,11 & 0,01 \\
\hline \multirow[t]{4}{*}{ I+ } & $0-10$ & 0,20 & 0,18 & 0,02 \\
\hline & $10-20$ & 0,17 & 0,03 & 0,14 \\
\hline & $20-30$ & 0,13 & 0,10 & 0,03 \\
\hline & $30-50$ & 0,13 & 0,07 & 0,06 \\
\hline
\end{tabular}

Fonte: Dados da pesquisa.

Comparando-se os valores de capacidade de campo e água disponível entre os sistemas de manejo estudados observa-se, em geral, nas duas primeiras camadas $(0-10$ e 
$10-20 \mathrm{~cm}$ de profundidade) nos tratamentos com queima e naqueles onde o material triturado foi deixado em cobertura, independente de adubação (Q-, Q+, C-, C+), valores variando de 0,06 a $0,12 \mathrm{~m}^{3} \mathrm{~m}^{-3}$ para a capacidade de campo e de 0,02 a $0,11 \mathrm{~m}^{3} \mathrm{~m}^{-3}$ para a água disponível. Nas demais camadas houve um ligeiro aumento nos valores dessas variáveis, o que pode estar relacionado ao maior teor de argila nas camadas mais profundas (Tabela 1). Apesar de mais elevados nas camadas mais profundas, estes resultados estão dentro da faixa estabelecida por Campbell (2006) para este tipo de solo e muito próximos aos resultados verificados na testemunha (CAP), indicando que nessa área os sistemas de uso adotados ao longo de 15 anos não promoveram alterações na disponibilidade de água no solo.

Quanto aos tratamentos com incorporação do material triturado (I- e I+) ocorreu resultado inverso aos demais. Nesse caso, é possível que a prática da incorporação da biomassa triturada tenha provocado uma ligeira inversão da granulometria do solo, aumentando o teor de argila e diminuindo o teor de areia na camada até $20 \mathrm{~cm}$, o que provocou um aumento significativo da quantidade de água no solo nas duas primeiras camadas analisadas, aumentando consideravelmente a umidade do solo na capacidade de campo e a água disponível nessas parcelas, os quais apresentaram valores muito superiores ao da faixa ideal.
Comparando os sistemas de manejo estudados quanto à quantidade de água no solo observa-se que, à exceção do $\mathrm{C}(-)$, todos os tratamentos baseados na trituração da capoeira apresentaram tendência em ser superiores aos baseados na queima da vegetação, os quais apresentaram resultados abaixo inclusive aos da testemunha (CAP). A ausência de cobertura do solo nos tratamentos com queima provocou uma sensível redução da capacidade de armazenamento de água pelo provável aumento da compactação do solo devido aos repetidos impactos das gotas de chuva, reduzindo as chances de infiltração de água, e pela formação de uma fina camada adensada na superfície do solo, o que pode ser comprovado a partir dos resultados de densidade do solo apresentados na Tabela 2. Já a maior retenção e disponibilidade de água às plantas no solo em plantio direto normalmente são atribuídas à barreira formada pelos resíduos (palha), que reduz a velocidade de escorrimento da água sobre o solo, melhorando a infiltração da água no perfil do solo, e diminuindo a evaporação da água na superfície devido à diminuição da temperatura e da incidência direta de raios solares sobre o solo (KATO, 1998).

Quanto ao ponto de murcha permanente, considerado o limite inferior de água no solo, os resultados estão em similaridade com trabalhos citados por Ghanbarian e Millán (2009) para solos com textura arenosa $\left(0,02 \mathrm{~m}^{3} \mathrm{~m}^{-3}\right.$ a $\left.0,08 \mathrm{~m}^{3} \mathrm{~m}^{-3}\right)$, não tendo sofrido alterações ao longo do 
tempo por influência dos sistemas de preparo do solo.

Resultados semelhantes ao desse estudo foram verificados por Dalmago et al. (2009) quando observaram que a disponibilidade de água às plantas no solo em plantio direto é maior que no solo em preparo convencional nas camadas mais próximas à superfície. Pesquisas relacionadas às condições hídricas do solo sob plantio direto na capoeira são ainda bastante incipientes, necessitando de estudos mais específicos para a avaliação do conteúdo de água no solo sob este sistema de uso e manejo.

\section{CONCLUSÕES}

O sistema baseado na trituração da capoeira aliado a complementação através da adubação mineral apresenta maior potencial para a manutenção da qualidade física do solo em relação ao sistema com queima da vegetação secundária no longo prazo;

A disponibilidade de água às plantas no solo sob trituração da capoeira é maior que no solo sob queima da capoeira nas camadas mais próximas à superfície.

\section{AGRADECIMENTO}

À Fundação de Amparo à Pesquisa do Estado do Pará-FAPESPA, pela concessão de bolsa de estudo.

\section{REFERÊNCIAS}

ARAUJO, M. A.; TORMENA, C. A.; SILVA, A. P. Propriedades físicas de um
Latossolo Vermelho distrófico cultivado e sob mata nativa. Revista Brasileira de Ciência do Solo, Viçosa, v. 28, n. 2, 2004. p. 337-345. ASSIS, R. L. de; LANÇAS, K. P. Avaliação dos atributos físicos de um Nitossolo Vermelho distroférrico sob sistema de plantio direto. Revista Brasileira de Ciência do Solo, Viçosa, v. 29, n. 4, 2005. p. 515-522.

BASTOS, T. X.; PACHECO, N. A. Características de Igarapé-Açu, PA e suas implicações para as culturas anuais: feijãocaupi, milho, arroz e mandioca. Belém: Embrapa Amazônia Oriental, 1999. 30 p. (Embrapa Amazônia Oriental. Boletim de Pesquisa, 25, 2007).

BERVALD, C. M. P. Tecnologia mecanizada em preparo de área sem queima no Nordeste Paraense. Santa Maria, 2005. 107 p. Dissertação (Mestrado em Engenharia Agrícola) - Universidade Federal de Santa Maria, RS, 2005.

CAMPBELL, G. Modeling avaliable soil moisture. Decagon Devices, 2006. Disponível em: <http://www.decagon.com. Acesso em: 20 dez. 2007.

CARDOSO JÚNIOR, E; KATO, O. R.; KATO, M. do S. A.; LOPES, S. da C.; SÁ, T. D. de A. Q. Métodos de preparo de área sobre algumas características físicas do solo e produção do maracujazeiro (Passiflora edulis) no Nordeste do Pará. 
Belém, PA: Embrapa Amazônia Oriental, 2007. $21 \mathrm{p}$.

COSTA, M. C. G. Calagem e Adubação no Primeiro Ano de Cultivo em Sistema de Corte e Trituração em Roraima. Boa Vista: Embrapa Roraima, 2008. 16 p. (Embrapa Roraima. Boletim de Pesquisa e desenvolvimento, 01).

DALAL, R. C.; CHAN, K. Y. Soil organic matter in rainfed cropping systems of the Australian cereal belt. Australian Journal of Soil Research. v. 39, n. 3, 2001. p. 435-464.

DALMAGO, G. A.; BERGAMASCHI, H.; BERGONCI, J. I.; KRÜGER, C. A. M. B.; COMIRAN, F.; HECKLER, B. M. M. Retenção e disponibilidade de água às plantas, em solo sob plantio direto e preparo convencional. Revista Brasileira de Engenharia Agrícola e Ambiental. [online]. 2009, vol.13, suppl., pp. 855-864. ISSN 18071929.

DESJARDINS, T., BARROS, E., SARRAZIN, M., GIRARDIN, C.; MARIOTTI, A. Effects of forest conversion to pasture on soil carbon content and dynamics in Brazilian Amazonia. Agriculture Ecosystems and Environment, v.103, p. 365-373, 2004.

DIAS JUNIOR, M.S. Compactação do solo. In: NOVAIS, R.F., ALVARES, V.H.; SCHAEFER, C.E.G.R. Tópicos em ciência do solo. Viçosa : SBCS, 2000. V.1, p.55-94.
EMBRAPA. Sistema Brasileiro de Classificação de Solos. Brasília, DF: Embrapa Produção de Informação; Rio de Janeiro: EMBRAPA - SNPS, 2006. 421p.

EMBRAPA. Centro Nacional de Pesquisa de Solos. Manual de métodos de análise de solo. Rio de Janeiro: Embrapa-CNPS, 1997. 212 p. (Embrapa-CNPS. Documentos, 1).

GAMA, M. A. P. Dinâmica do fósforo em solo submetido a sistemas de preparo alternativos ao corte e queima no Nordeste Paraense. Piracicaba: ESALQ, 2002. 96 p. Tese (Doutorado em Agronomia)- ESALQ, Piracicaba, 2002.

GHANBARIAN, A.; MILLÁN, H. The reationship between surface fractal dimension and soil water content at permanent wilting point. In: Geoderma, Ed. 151, p.224-232, 2009.

HILLEL, D. Solo e água, fenômenos e princípios físicos. Porto Alegre, Universidade Federal do Rio Grande do Sul, 1970. 231p.

INSTITUTO BRASILEIRO DE GEOGRAFIA E ESTATÍSTICA. Pesquisa Agrícola Municipal. Disponível em: <http://www.ibge.gov.br>. Acesso em: 7 nov. 2011.

KATO, M. S. A. Fire free land preparation as an atlternative to slash-and-burn agriculture in the Bragantina region: crop 
performance and Phosphorus dynamics. Göttingen: Cuvillier, 1998. 144 p.

KIEHL, E. J. Manual de edafologia: relações solo-planta. São Paulo: Ceres, 1979, 262 p.

LINS-TEIXEIRA, A.; Tapia-Coral, S. C.; LUIZÃO, F. J.; MORAIS, J. W.; WANDELLI, E. Macro-invertebrados do solo em capoeiras trituradas usadas como alternativa ao uso do fogo no assentamento Tarumã-Mirim, Amazonas. In.: VIII CONGRESSO DE ECOLOGIA DO BRASIL, Caxambu, 2007, p. 1-2. Disponível em: $\quad<h t t p: / / w w w . s e b-$ ecologia.org.br/viiiceb/pdf/251.pdf>. Acesso em: 07 set 2011.

LITTELL, R. C.; MILIKEN, G. A.; STROUP, W. W.; WOLFINGER, R.; SCHABENBERBER, P. D. SAS System for Mixed Models. $2^{\text {nd }}$ Edition. SAS Publishing. 840p. 2006.

LOCATELLI, M.; MARCOLAN, A. L.; GONÇALVES, E. L.; SILVA, D. F. da, MARCANTE, P. H. Matéria orgânica, densidade e porosidade do solo submetido à trituração de capoeira em Porto Velho, Rondônia. In.: XXXIII CONGRESSO BRASILEIRO DE CIÊNCIA DO SOLO, Uberlândia. Anais... Disponível em: <http://www.alice.cnptia.embrapa.br/bitstrea m/doc/897661/1/23421.PDF>. Acesso em: 19 jan 2012.
MAFRA, N. M. C. Erosão e planificação de uso do solo. In.: Antonio José Teixeira Guerra; Antonio Soares da Silva; Rosangela Garrido Machado botelho (org). Erosão e conservação dos solos: conceitos, temas e aplicações. 5 ed. Rio de Janeiro. Bertrand Brasil. 2010. p. 301-322.

MARCOLAN, A. L.; LOCATELLI, M.; FERNANDES, S. R. Densidade e resistência à

penetração de um Latossolo pelo corte e trituração da capoeira, substituindo a derruba e queima, no preparo da área para plantio direto. In: CONGRESSO BRASILEIRO DE CIÊNCIA DO SOLO, 32, 2009, Fortaleza. Anais... Fortaleza: SBCS, 2009. 1 CD ROM.

MULUMBA, L.N.; LAL, R. Mulching effects on selected soil physical properties. Soil and Tillage Research, v.98, p.106-111, 2008.

OLIVEIRA, I. P. de; COSTA, K. A. de P.; RODRIGUES, C.;

MACEDO, F. da. R; MOREIRA, F. P.; SANTOS, K. J. G. dos. Manutenção e correção da fertilidade do solo para inserção do cerrado no processo produtivo. Revista Eletrônica Faculdade Montes Belos, Goiás, v.1, n.1, p. 50-64, 2005.

OLIVEIRA， L.; FERREIRA， M.S.G.; SABOGAL, C. Estudo da capoeira. In: CARVALHEIRO, K.O.; GONÇALVES, D.A.; MATTOS, M.M.; FERREIRA, M.S.G. 
(Ed). Agricultura familiar no Nordeste

Paraense: informações preliminares como contribuição ao manejo sustentável da capoeira. Belém: Embrapa Amazônia Oriental; Cifor, 2001. p. 63-70.

SANTOS, G. A. dos; DIAS JUNIOR, M. de S.; GUIMARÃES, P. T. G.; FURTINI NETO, A. E. Diferentes graus de compactação e fornecimento de fósforo influenciando no crescimento de plantas de milho (Zea mays L.) cultivadas em solos distintos. Ciência e Agrotecnologia, Lavras, v. 29, n. 4, 2005. p. 740-752.

SCHWARTZ, G. Manejo sustentável de florestas secundárias: espécies potenciais no Nordeste do Pará, Brasil. Amazônia: Ciência \& Desenvolvimento, Belém, v. 3, n. 5, 2007. p. $125-147$.

SILVA, D. M. M. H. da. Macrofauna edáfica, biomassa microbiana e qualidade do solo em área cultivada no cerrado amapaense com e sem uso do fogo e adubação alternativa. 2009. 55 p. Dissertação (Mestrado em Biodiversidade Tropical) - Universidade Federal do Amapá, Macapá, 2009.

SOUZA, L. D. N. de. Adubação orgânica. São Paulo: Editora Tecnoprint, 1989. 116 p.

TORRES, R. Regime hídrico do solo. Disponível em: $<$ http://www.ebah.com.br/content/ABAAAA WZsAF/regime-hidrico-solo. Acesso em: 20 jun. 2012.

TRINDADE, E. F. da S; RODRIGUES, T. E. ; CARVAlhO, E.J.M. ; CORRÊA, P. C. S. Matéria orgânica e atributos físicos de um Argissolo Amarelo distrófico no Nordeste Paraense. Amazônia: Ciência \& Desenvolvimento, Belém, v. 5, n. 9, 2009. p. 186-198.

WOLTERS, V. Invertebrate control of soil organic matter stability. Biology and Fertility of Soils, Berlin, v. 31, p. 1-19, 2000. 